Purdue University

Purdue e-Pubs

2014

Latent-Heat Augmentation of Thermocline Energy Storage for Concentrating Solar Power - A SystemLevel Assessment

\author{
S. M. Flueckiger \\ Purdue University \\ S V. Garimella \\ Purdue University, sureshg@purdue.edu
}

Follow this and additional works at: http://docs.lib.purdue.edu/coolingpubs

Flueckiger, S. M. and Garimella, S V., "Latent-Heat Augmentation of Thermocline Energy Storage for Concentrating Solar Power - A System-Level Assessment" (2014). CTRC Research Publications. Paper 205.

http://dx.doi.org/http://dx.doi.org/10.1016/j.apenergy.2013.11.059

This document has been made available through Purdue e-Pubs, a service of the Purdue University Libraries. Please contact epubs@purdue.edu for additional information. 


\title{
Latent heat augmentation of thermocline energy storage for concentrating solar power - a system-level assessment ${ }^{\star}$
}

\author{
Scott M. Flueckiger and Suresh V. Garimella**
}

\author{
School of Mechanical Engineering \\ Purdue University
}

West Lafayette, IN 47907-2088 USA

*Revised for publication in Applied Energy

**Author to whom correspondence to be addressed: Tel.: (765) 494-5621, Fax: (765) 494-0539,

E-mail: sureshg@purdue.edu 


\begin{abstract}
Molten-salt thermocline tanks are a low-cost energy storage option for concentrating solar power plants. Despite the potential economic advantage, the capacity of thermocline tanks to store sufficient amounts of high-temperature heat is limited by the low energy density of the constituent sensible-heat storage media. A promising design modification replaces conventional rock filler inside the tank with an encapsulated phase-change material (PCM), contributing a latent heat storage mechanism to increase the overall energy density. The current study presents a new finite-volume approach to simulate mass and energy transport inside a latent heat thermocline tank at low computational cost. This storage model is then integrated into a systemlevel model of a molten-salt power tower plant to inform tank operation with respect to realistic solar collection and power production. With this system model, PCMs with different melting temperatures and heats of fusion are evaluated for their viability in latent heat storage for solar plants.
\end{abstract}

Thermocline tanks filled with a single PCM do not yield a substantial increase in annual storage or plant output over a conventional rock-filled tank of equal size. As the melting temperature and heat of fusion are increased, the ability of the PCM to support steam generation improves but the corresponding ability of the thermocline tank to utilize this available latent heat decreases. This trend results from an inherent deconstruction of the heat-exchange region inside the tank between sensible and latent heat transfer, preventing effective use of the added phase change for daily plant operations. This problem can be circumvented with a cascaded filler structure composed of multiple PCMs with their melting temperatures tuned along the tank height. However, storage benefits with these cascaded tank structures are shown to be highly sensitive to the proper selection of the PCM melting points relative to the thermocline tank operating temperatures. 
Keywords: Molten-salt thermocline tank, latent heat storage, concentrating solar power, power tower 


\section{Introduction}

A major roadblock to the continued growth and maturing of concentrating solar power (CSP) technology is the intermittent availability of sunlight across multiple time scales. Thermal energy storage is therefore essential for decoupling power production from solar collection, enabling the power plant to satisfy electrical demand independent of the prevalent sunlight conditions. Existing CSP plants employ a sensible heat-based system known as two-tank storage, where excess hot and cold heat transfer fluid (e.g., molten salt) is stored in two separate tank volumes. While a simple and effective storage method, the construction of two tanks carries significant physical and cost redundancy.

A low-cost alternative to the two-tank concept is to store the hot and cold molten salt together inside a single tank volume, in a so-called thermocline. Physical separation of the hot and cold regions is sustained via buoyancy forces (the hot salt is lighter than the cold salt) which help stratify the two isothermal regions along the vertical direction. A narrow layer of large temperature gradient develops at the interface between the hot and cold regions and is known as the thermocline or heat-exchange region. The resultant sigmoid-shaped temperature profile, illustrated in Figure 1, travels up and down the height of the tank as the system is cyclically filled with hot and cold molten salt. In addition to the salt, the thermocline tank is also filled with an inexpensive granulated material that reduces the volume of higher-cost salt required for storage and helps mitigate fluid mixing forces that are detrimental to the thermal stratification. A material study by Pacheco et al. [1] determined that quartzite rock and silica sand were the most attractive filler materials in terms of cost, chemical inertness, and physical stability in a molten salt bath. 
Despite its low capital cost and successful technical demonstration of the concept [1-7], the dual-media thermocline tank presents several design challenges that continue to inhibit commercialization. As a device that stores energy solely by sensible heat, the low energy density of the molten-salt and rock volume requires large tank diameters to store sufficient quantities of high-temperature heat (the tank height itself is constrained by the bearing capacity of the underlying soil). A large tank diameter is undesirable as it increases the potential for both maldistribution of fluid flow inside the porous bed and a structural instability known as thermal ratcheting $[8,9]$. A design modification that has been proposed for reducing the tank size (by increasing energy density) is a substitution of the internal filler rock with a phase-change material (PCM). During storage operations, the PCM undergoes repeated melting and solidification in response to forced convective heat exchange with the surrounding molten-salt flow, contributing an additional latent heat storage mechanism inside the tank. For practical implementation, small volumes of PCM are encapsulated in a protective liner to prevent physical mixing with the salt. The tank is then filled with these capsules to mimic the unconsolidated porous structure of the conventional rock filler.

Study of the latent heat thermocline tank concept has largely focused on the behavior of encapsulated PCMs. Pendyala et al. [10] investigated the encapsulation process and presented a fabrication technique in which a liner of silicon dioxide self-assembles around a pellet of sodium nitrate PCM. The coating process exhibited uniformity and repeatability problems, but a portion of the generated capsules withstood multiple cycles of heating and cooling. At the storage device level, Felix Regin et al. [11] developed a finite-difference model of an encapsulated PCM-filled tank for solar water-heating applications. Charge and discharge rates of the internal latent heat were reported to improve with reduced capsule diameter. Nithyanandam et al. [12] 
developed a finite-volume model of a latent heat thermocline tank with encapsulated PCM for molten-salt CSP plants; capsule radius was optimized with respect to utilization of the latent heat capacity and the required pumping power for fluid flow through the porous bed.

Computational study of the latent heat thermocline tank has not been performed to date at the power plant system level, i.e., in conjunction with solar collection and power production processes. Given the diurnal and seasonal intermittency of the available sunlight, this systemlevel perspective is essential to the understanding of how the storage tank behaves in the context of actual CSP plant operation. The present work addresses this need with a new finite-volume simulation of a latent heat thermocline tank, replacing the internal quartzite rock with a bed of encapsulated phase-change material. This storage model is then integrated into a system model of a $100 \mathrm{MW}_{\mathrm{e}}$ molten-salt power tower plant. The objective of the system modeling effort is to ascertain the viability of the latent heat thermocline concept for CSP applications. A parametric study of the PCM melting temperature and heat of fusion serves to identify the optimal ranges of values that would maximize the annual power plant output. System performance with a conventional rock-filled (sensible heat-based) thermocline tank of equal size serves as the benchmark for comparison.

\section{Numerical Model}

An illustration of the latent heat thermocline tank is provided in Figure 2. The tank interior includes a dual-media porous region, composed of molten salt and PCM capsules, as well as a liquid heel of salt above the capsules. For the current study, molten salt is represented with a commercial eutectic mixture known as Solar Salt (60 wt.\% $\mathrm{NaNO}_{3}, 40$ wt.\% $\mathrm{KNO}_{3}$ ) which operates between $300{ }^{\circ} \mathrm{C}$ and $600{ }^{\circ} \mathrm{C}$. Physical properties of the salt are known functions 
of temperature $[13,14]$. The specific heat is relatively constant across the stated temperature span and is approximated with an average value of $1520 \mathrm{~J} / \mathrm{kg}-\mathrm{K}$.

To facilitate direct comparison with thermocline tanks that use conventional sensible-heat filler materials, a hypothetical PCM filler is considered with density, specific heat, and thermal conductivity equivalent to those of quartzite rock: $2500 \mathrm{~kg} / \mathrm{m}^{3}, 830 \mathrm{~J} / \mathrm{kg}-\mathrm{K}$, and $5 \mathrm{~W} / \mathrm{m}-\mathrm{K}$, respectively $[15,16]$. In reality, phase-change materials suitable for latent heat storage tend to have lower thermal conductivities as well as densities that vary with temperature. The current study neglects these material deficiencies of PCMs in order to provide an objective and abstracted assessment of the storage capacity added by the latent heat mechanism. Cyclic phase change is governed by the heat of fusion $\left(h_{f s}\right)$ and the melting temperature of the material, which are treated as user-defined inputs. The protective capsule liner surrounding the PCM is assumed to be thin, and any thermal resistance posed is neglected. Thermal energy storage occurs in both the porous PCM-filled bed and the pure liquid heel, as explained in the following sections.

\subsection{Porous region}

Mass and momentum transport of molten salt inside the thermocline porous bed are governed by the following equations:

$$
\begin{aligned}
& \frac{\partial \varepsilon \rho_{l}}{\partial t}+\nabla \cdot\left(\rho_{l} \mathrm{u}\right)=0 \\
& \frac{\partial \rho_{l} \mathrm{u}}{\partial t}+\nabla \cdot\left(\rho_{l} \frac{\mathrm{u} \mathrm{u}}{\varepsilon}\right)=-\varepsilon \nabla p+\nabla \cdot \tau+\rho_{1} \mathrm{~g}+\varepsilon\left(\frac{\mu}{K} \mathrm{u}+\frac{F}{\sqrt{K}} \rho_{l}|\mathrm{u}| \mathrm{u}\right)
\end{aligned}
$$

It should be noted that thermocline tanks generally exhibit low fluid velocities, approximating laminar, plug-flow conditions. Under these flow conditions, the momentum equation simplifies to the Darcy-Forchheimer equation. 
Energy transport in the porous region is formulated with separate equations for the liquid molten salt (subscript $l$ ) and the PCM filler (subscript $s$ ):

$$
\begin{aligned}
& \frac{\partial\left[\varepsilon \rho_{l} C_{P, l}\left(T_{l}-T_{c}\right)\right]}{\partial t}+\nabla \cdot\left[\rho_{l} \mathrm{u} C_{P, l}\left(T_{l}-T_{c}\right)\right]=\nabla \cdot\left(k_{e f f} \nabla T_{l}\right)+h_{i}\left(T_{s}-T_{l}\right) \\
& \frac{\partial\left[(1-\varepsilon) \rho_{s} C_{P, s}\left(T_{s}-T_{c}\right)\right]}{\partial t}=-h_{i}\left(T_{s}-T_{l}\right)+\frac{\partial\left[(1-\varepsilon) \rho_{s} L\right]}{\partial t}
\end{aligned}
$$

Thermal diffusion is neglected in Eq. 4 as the temperature in each PCM capsule is assumed to be uniform. The porous structure influences diffusion in the surrounding molten salt that is characterized by an effective thermal conductivity calculated from a correlation [17]. Forced convection between the molten salt and PCM capsule is characterized with the Wakao and Kaguei correlation [18].

A second transient source term is included in Eq. 4 to represent the cyclic melting and solidifying of the PCM filler. The current study applies the enthalpy method developed by Voller and Prakash [19], where the latent thermal energy $(L)$ contained by the PCM is proportional to its solid fraction $\left(F_{s}\right)$ :

$$
L=h_{f s}\left(1-F_{s}\right)
$$

For numerical stability, the PCM solid fraction is assumed to vary linearly between the solidus $\left(T_{s o l}=T_{m}-e\right)$ and the liquidus $\left(T_{l i q}=T_{m}+e\right)$ temperatures over a small mushy region (in which both liquid and solid phases exist in equilibrium) half span temperature range $e$ of $1 \mathrm{~K}$ :

$$
F_{s}=\left\{\begin{array}{lc}
1 & T_{s} \leq T_{s o l} \\
\frac{T_{l i q}-T_{s}}{2 e} & T_{s o l}<T_{s} \leq T_{l i q} \\
0 & T_{s}>T_{l i q}
\end{array}\right.
$$


The thermocline tank wall is assumed to be well-insulated, which simplifies Eq. 3 to a one-dimensional formulation along the axial direction. To nondimensionalize the governing energy equations, the molten-salt and PCM temperatures are normalized with respect to the hot and cold operating limits:

$$
\Theta=\frac{T-T_{c}}{T_{h}-T_{c}}
$$

The transport equations are solved using a finite-volume discretization of the porous bed along the axial direction. The molten-salt velocity field along the discretized porous bed is determined from mass conservation (Eq. 1). The energy transport equations are then converted to algebraic relationships as follows. A first-order implicit method is applied for discretization of the temporal terms. The convective flux term in the fluid energy transport (Eq. 3) is discretized with the quadratic flux limiter, a quasi-second-order local extrema-diminishing scheme. A Picard iteration scheme is implemented to resolve nonlinearity in Eq. 3 as well as the forced convection coupling with Eq. 4. The resultant equations are then solved at each time step with a tridiagonal matrix algorithm written in C. This algorithm is repeated for up to 75 iterations or until the nondimensional residual error reduces to less than $10^{-6}$. Validation of the thermal model and the solution technique were previously demonstrated with a simulation of the 2.3 $\mathrm{MWh}_{\mathrm{t}}$ thermocline tank constructed by Sandia National Labs $[1,7]$.

Boundary conditions for the continuity and energy equations are informed by the mode of tank operation. During a charge process, hot molten salt from the liquid heel (discussed in the next section) enters the top of the porous bed at a uniform velocity. At the same time, cold salt exiting the floor of the bed is simulated with an outflow boundary condition. During the reverse discharge process, uniform cold salt is supplied to the bottom of the bed. An outflow boundary condition is then applied for the hot salt exiting the top of the porous bed. Thermal diffusion 
from the liquid heel to the underlying porous bed is treated with a Dirichlet boundary condition equal to the current temperature of the heel. Another Dirichlet condition is enforced at the tank floor, with a fixed temperature equal to the cold operating limit.

\subsection{Liquid heel}

Given that the molten-salt density decreases with temperature, the thermocline tank cannot realistically be modeled as a control volume. The liquid level inside the tank rises during a charge (when hot salt is added) and falls during a discharge (when cold salt is added). A pure molten-salt region must therefore be maintained above the porous bed (i.e., the PCM capsules) to prevent dryout in the porous region. Energy transport in this additional fluid region cannot be solved with a conventional finite-volume method as the heel thickness varies with time. The heel is instead approximated as an isothermal region, where temperature is determined from the known mass and energy content:

$$
T_{\text {heel }}=T_{c}+\frac{E_{\text {heel }}}{m_{\text {heel }} C_{P, l}}
$$

During daylight hours, the solar receiver supplies hot molten salt to this heel at $600{ }^{\circ} \mathrm{C}$. When the heel warms to a temperature hot enough to support power production, salt is extracted from the heel for steam generation in the Rankine cycle heat exchangers. Mass and energy transport between the heel and the underlying porous bed again depends on the tank operating mode as discussed in the previous section.

\subsection{System model}

The low computing cost of the thermocline model allows for integration into a systemlevel model of a CSP plant. Such a model was previously developed by Flueckiger et al. [7] for 
a molten-salt power tower plant with sensible-heat thermocline storage and is summarized here. The power tower plant is desired to provide a net turbine output of $100 \mathrm{MW}_{\mathrm{e}}$ at a solar multiple of 2.3. The surround-style heliostat field and solar receiver are sized with DELSOL, a power tower design tool developed by Sandia National Laboratories [20]. The model field includes $1,170,000 \mathrm{~m}^{2}$ of reflector area and a receiver tower height of $194.7 \mathrm{~m}$. The solar receiver atop this tower is an external cylinder design with a diameter of $21 \mathrm{~m}$ and a height of $18 \mathrm{~m}$. Sunlight data for collector analysis are taken from direct normal irradiance (DNI) measurements near Barstow, CA, selected for its excellent annual insolation of $2700 \mathrm{kWh} / \mathrm{m}^{2}$. This dataset includes recorded DNI at 15-minute intervals from January 1 to December 31 of 1977.

From the available sunlight data, incident thermal power reflected onto the solar receiver is calculated with SOLERGY, a system-performance model for power tower plants developed by Sandia National Laboratories [21]. At each 15-minute interval, SOLERGY calculates the current solar collection efficiency of the heliostat field and then solves for the power absorbed by the molten salt traveling inside the solar receiver, correcting for both convection and radiation losses. The mass flow rate inside the receiver is controlled in response to changes in DNI such that molten salt always exits the receiver at $600{ }^{\circ} \mathrm{C}$. In practice, this set temperature is maintained through a combination of temperature feed-back and irradiance feed-forward controls [22]. This year-long receiver performance is assumed to be independent of the downstream thermocline tank or power block operations.

It should be noted that no storage bypass line is included between the solar receiver and Rankine cycle heat exchangers; thus all molten salt exiting the receiver is directed to the liquid heel of the thermocline tank. Once the tank is charged to a sufficient energy content, hot salt is extracted from this heel and sent to the power block. A schematic diagram of the power block is 
shown in Figure 3. The three heat exchangers (preheater, evaporator, and superheater) serve to transfer thermal power from the supplied molten salt to the steam working fluid. Under nameplate or rated conditions, molten salt enters the superheater at $600{ }^{\circ} \mathrm{C}$ and exits the preheater at $300{ }^{\circ} \mathrm{C}$. The cold salt is returned either to the thermocline tank or to the solar receiver. At the same time, water enters the preheater and converts to steam. The generated steam then travels through a two-stage non-reheat turbine for power production. Detailed discussion of this Rankine cycle model is available in [7]. Sizing of the power block includes a $10.3 \%$ overdesign to accommodate parasitic electrical demands within the power plant [20], equivalent to a gross output of $111.5 \mathrm{MW}_{\mathrm{e}}$. At rated load, the thermal efficiency of the cycle is $41.2 \%$ and requires a heat input of $270.9 \mathrm{MW}_{\mathrm{t}}$.

Prior to any power production, both the heat exchangers and steam Rankine cycle must be conditioned for operation through a so-called startup process. This process includes warming of the heat exchangers, synchronization of the turbine with the electric generator, and ramp-up to rated gross output. During the heat exchanger warming and turbine synchronization stage, the thermocline tank supplies hot molten salt to the model power block at the minimum thermal rating, but with no work output. After synchronization is complete, the turbine initiates power production with a linear ramp-up to its rated performance. The required time interval for these actions is a function of the initial turbine temperature prior to startup, itself a function of the time elapsed after the previous shutdown [23].

System-level control of the thermocline tank is informed by the transient operation of both the solar receiver and the power block [7]. During sunlight hours, the solar receiver activates and supplies hot molten salt to the tank for storage. When a sufficient amount of energy is stored, the tank supplies hot salt to the power block for steam generation and associated 
power output. The flow direction inside the thermocline tank (charge or discharge) is therefore dictated by the relative operational needs of the solar receiver and the power block. Additional constraints are enforced to prohibit excessive cyclic system operation that may cause undue wear on the thermocline tank and power block. For example, random cloud transients may generate sporadic DNI losses during daylight hours and subject the thermocline to impractical operating conditions. Startup of the power is therefore delayed until the tank can support at least two hours of utilizable heat for steam generation to avoid rapid on-off toggling of either the storage system or the Rankine cycle.

Given that the thermocline tank supports a continuous thermal stratification of molten salt, the temperature of salt exiting the tank will not be fixed in time. At low-energy states, the volume of hot salt inside the tank is exhausted and the exit temperature (supplied to the superheater) decreases below $600{ }^{\circ} \mathrm{C}$. This reduction in exergy is carried through the subsequent steam generation and reduces the turbine inlet temperature. Power production is sustained by adjusting the steam pressure and mass flow rate in response to the temperature decrease, in a process known as sliding-pressure operation. In the current study, this derated performance terminates when power production equals $30 \%$ of the rated gross output, associated with an available molten-salt temperature of $473{ }^{\circ} \mathrm{C}(\Theta=0.58)$.

Molten-salt temperature can fluctuate similarly at the bottom thermocline tank exit. When solar collection exceeds power demand for steam generation, the heat-exchange region travels down the porous bed as the tank is charged with hot salt. When this region reaches the tank floor, the temperature of the cold salt exiting the tank will increase. This then elevates the cold salt temperature returning to the solar receiver. To prevent overheating inside the receiver, the thermocline cold exit temperature is limited to $400{ }^{\circ} \mathrm{C}(\Theta=0.33)$. At this threshold, the 
thermocline tank is forced into a standby condition while the solar collection system defocuses heliostats such that the receiver absorbs only enough energy to satisfy the thermal demand for steam generation. The energy lost due to storage limitations and consequent heliostat defocusing is known as thermal energy discard. Tank standby and energy discard persist until incident solar radiation decays, and discharge of the thermocline tank is again initiated to sustain rated electricity generation at the reduced receiver power.

Given the restrictions on both supply and return temperature, it is noted that any molten salt below $400{ }^{\circ} \mathrm{C}$ can be returned to the solar receiver, while any salt above $473{ }^{\circ} \mathrm{C}$ can be supplied to the power block. Thus, any salt region that is between these temperature limits within the thermocline tank constitutes a thermal dead zone that is not useful for either solar collection or steam generation.

\section{Results and Discussion}

A system-level study of a $100 \mathrm{MW}_{\mathrm{e}}$ molten-salt power tower plant is now conducted with the latent-heat-augmented thermocline concept to quantify the plant performance benefits over a conventional sensible heat thermocline. As previously discussed, this one-to-one comparison is enabled by implementing a bed of (hypothetical) phase-change material with sensible transport properties equivalent to quartzite rock. The latent transport properties, viz., heat of fusion and melting temperature, are varied to determine their influence on storage and plant performance. The magnitude of the heat of fusion inside the PCM is expressed relative to the fixed sensible heat capacity as an inverse Stefan number:

$$
\frac{1}{\text { Ste }}=\frac{h_{f s}}{C_{P, s}\left(T_{h}-T_{c}\right)}
$$


The current study investigates three inverse Stefan numbers: 0 (i.e., quartzite rock), 0.25, and 0.5. The heats of fusion corresponding to the non-zero inverse Stefan numbers are $62.25 \mathrm{~kJ} / \mathrm{kg}$ and $124.5 \mathrm{~kJ} / \mathrm{kg}$, respectively. Relative to actual candidate PCMs, these properties represent lower, conservative values for latent heat storage. The PCM is also investigated at five different melting temperatures within the operating span of the molten salt; $315{ }^{\circ} \mathrm{C}(\Theta=0.05), 375{ }^{\circ} \mathrm{C}(\Theta$ $=0.25), 450{ }^{\circ} \mathrm{C}(\Theta=0.5), 525^{\circ} \mathrm{C}(\Theta=0.75)$, and $585^{\circ} \mathrm{C}(\Theta=0.95)$. The different porous bed conditions investigated are summarized in Table 1.

Simulation of each thermocline filler bed composition is performed in conjunction with the power-tower system model. In all models, the tank is sized to contain eight hours of sensible heat, plus an additional half-hour overdesign, totaling $2300 \mathrm{MWh}_{\mathrm{t}}$. The volumetric overdesign is needed to accommodate both the requisite amount of sensible heat for storage and the underlying cold and transitional temperatures associated with the heat-exchange region. A design study by the Electric Power Research Institute reported that thermocline tanks with a typical foundation are limited to a maximum liquid level of 39 feet $(11.9 \mathrm{~m})$ due to the bearing capacity of the underlying soil [24]; the height of the porous bed is therefore fixed to $11 \mathrm{~m}$. Given the sensible energy densities of the molten salt and filler material, the thermocline tank requires a diameter of $36.5 \mathrm{~m}$ to satisfy the required storage capacity. The PCM capsules are sized to an effective diameter of $1 \mathrm{~cm}$ and assumed to form a 0.22 porosity bed, similar to previous reports for quartzite rock [1]. With the tank sized to a fixed sensible-heat capacity, the latent heat of the PCM filler adds either $388 \mathrm{MWh}_{\mathrm{t}}(1 / \mathrm{Ste}=0.25)$ or $766 \mathrm{MWh}_{\mathrm{t}}(1 / \mathrm{Ste}=0.5)$ to the maximum storage capacity. The benefit of this supplement should then manifest in a greater annual energy storage inside the tank, and thus a greater annual turbine output. 
Prior to storage and power block simulation, the year-long performance of the heliostat field and solar receiver are first calculated with SOLERGY using recorded sunlight data. The thermocline tank porous bed and liquid heel are then both initialized to the cold temperature limit of $300{ }^{\circ} \mathrm{C}$. The porous bed geometry is discretized with a cell length of $1.1 \mathrm{~cm}$ (1000 cells) along the axial direction and a time step of 3 seconds. Each tank design is then subjected to a full year of operation, informed by the SOLERGY solar receiver data. The influence of supplemental latent heat capacity in the thermocline tank on CSP plant performance is monitored with respect to annual capacity factor, thermal energy discard, and utilization of the storage energy capacity.

\subsection{Annual CSP plant performance}

Power production from the CSP plant is characterized by the capacity factor, i.e., the ratio of net turbine output to the theoretical maximum (constant output at rated load). The annual plant capacity factors for all 11 thermocline filler cases are plotted in Figure 4a. The baseline quartzite-filled tank (case 1) exhibits an annual capacity factor of 0.533 . A majority of the PCMfilled tanks have similar values to quartzite, implying minimal impact from the addition of latent heat. PCMs with low melting temperatures $\left(\Theta_{\mathrm{m}}=0.05,0.25\right)$ result in a slight increase relative to quartzite, while PCMs with high melting temperatures $\left(\Theta_{\mathrm{m}}=0.75,0.95\right)$ show a slight decrease. The intermediate melting temperature of $\Theta_{\mathrm{m}}=0.5$ exhibits the largest decrease, which worsens with increased heat of fusion (i.e., latent heat capacity), represented by the inverse

Stefan number of the PCM. For all other PCM melting points, variation of the material heat of fusion does not influence annual power production. 
The annual discard of thermal energy from the solar collector due to saturation of the thermocline storage capacity is plotted in Figure 4b. As previously discussed, storage saturation occurs when cold salt exiting the tank floor increases to $400{ }^{\circ} \mathrm{C}$. The discard is normalized with respect to the total sunlight available to provide insight on how well the thermocline tank is sized relative to the surrounding power plant. During a year of operation, the conventional thermocline tank (case 1) discards $11.6 \%$ of the available sunlight. As with capacity factor, this performance is not benefitted by the addition of supplemental latent heat. PCMs with low melting temperature exhibit a slight decrease in discard relative to quartzite, while the high melting temperatures perform almost identically to quartzite. The intermediate melting temperature of $\Theta_{\mathrm{m}}=0.5$ again presents the worst-case condition with an increased annual discard up to $25.5 \%$.

A comparison of Fig. 4a and Fig. 4b illustrates a complementary trend between thermal energy discard and capacity factor. When discard increases, less thermal energy is harnessed by the thermocline tank and power block, leading to the observed reduction in electricity generation as expected. The model data reveal that the addition of latent heat (at no change in sensible heat capacity) to the thermocline filler material does not provide substantial benefits with respect to CSP plant performance. Instead, a majority of the PCM fillers result in a decrease in capacity factor, indicating that a larger thermocline tank would be required to match the plant performance achieved with conventional quartzite rock. While the latent heat provided by the PCM filler increases the available total storage capacity potential, the addition also appears to hinder the ability of the thermocline tank to harness this capacity. 


\subsection{Thermocline tank utilization}

During CSP plant operation, the utilization of the thermocline tank is indicated by the energy content inside the tank relative to its theoretical energy capacity (the amount of heat stored if the entire molten-salt and filler volumes are heated to the hot operating limit of $600{ }^{\circ} \mathrm{C}$ ). The theoretical energy capacity is not observed in practice due to the constant presence of the heat-exchange region inside the tank. The actual maximum utilization is observed when the thermocline tank reaches its saturation condition and is prevented from accepting any additional excess heat from the solar receiver. Figure 5 illustrates this maximum utilization for all 11 filler conditions, corresponding to when the tank becomes saturated during plant operation. While these tank saturations occur multiple times throughout the year, the amount of thermal energy stored at this condition varies by less than $1 \%$ for the same tank between instances. Utilization of sensible heat and latent heat in the porous bed are calculated and plotted separately to isolate the influence of the added phase change:

$$
\begin{aligned}
& U_{\text {sen }}=\frac{1}{h} \sum_{i=1}^{N} \frac{\left(\varepsilon \rho_{l} C_{P, l} \Theta_{l}+(1-\varepsilon) \rho_{s} C_{P, s} \Theta_{s}\right)_{i} \Delta x}{\varepsilon \rho_{l} C_{P, l}+(1-\varepsilon) \rho_{s} C_{P, s}} \\
& U_{\text {lat }}=\frac{1}{h} \sum_{i=1}^{N}\left(1-F_{s}\right)_{i} \Delta x
\end{aligned}
$$

As seen in Fig. 5a, the conventional quartzite-filled thermocline tank utilizes up to $93.8 \%$ of the sensible heat capacity. For the PCM fillers, maximum utilization varies with respect to both melting temperature and heat of fusion. While the latent thermal energy capacity is unrelated to the sensible heat capacity of the tank, the phase change process does influence heat transfer between the molten salt and the PCM filler. PCM fillers with low melting temperature result in greater sensible heat storage than quartzite and further improve with increased heat of fusion. In contrast, PCM fillers with intermediate or high melting temperatures enable less 
sensible heat storage than quartzite and further degrade with increased heat of fusion, as explained in the next section. The worst-case-performance is observed for the intermediate normalized PCM melt temperature of 0.5 , which only utilizes $75.1 \%$ of the available sensible heat capacity among the cases considered.

Maximum utilization of the latent heat inside the thermocline tank is plotted in Fig. 5b. Unlike the sensible heat capacity, the magnitude of latent heat available inside the tank is not fixed but is proportional to the user-defined PCM heat of fusion. The conventional quartzite rock filler (case 1) provides no latent heat and is thus omitted from the figure. The remaining cases illustrate a large variation with respect to the PCM melt properties. While low melting temperatures achieve $100 \%$ utilization (indicating that all PCM converts to a liquid phase), this performance deteriorates with increasing melting point and heat of fusion. For the highest melting temperature and heat of fusion condition (case 11), the PCM-filled thermocline tank only utilizes $9.4 \%$ of the available latent heat capacity at saturation.

The trends observed in Fig. 5b indicate that as the thermodynamic quality of the PCM increases (i.e., a higher melting point or heat of fusion), the ability of the thermocline tank to harness the available latent heat decreases. This behavior explains why the PCM-filled tanks did not significantly outperform a quartzite-filled tank of equal size with respect to net power production (Fig. 4a) or annual thermal energy discard (Fig. 4b). The latent heat thermocline tank only stores more thermal energy than a quartzite-filled tank when the PCM filler melts at low temperatures; however, at such low temperatures this additional latent heat energy is not viable for steam generation. At higher PCM melting points, the supplemental energy capacity added by latent heat is offset by the reduction in actual phase change. 


\subsection{Heat-exchange region}

The poor utilization of latent heat at high PCM melting points is explained by the behavior of the heat-exchange region inside the porous bed. As discussed before, the heatexchange region travels up and down the height of the tank in response to cyclic charging and discharging of the system. For a conventional sensible-heat thermocline tank, the relation between the heat-exchange region travel rate and the inlet velocity of the molten salt is obtained from an energy balance on the region [15]:

$$
\mathrm{v}_{s e n}=\frac{\rho_{l, i n} C_{P, l}}{\varepsilon \rho_{l, i n} C_{P, l}+(1-\varepsilon) \rho_{s} C_{P, s}} u_{i n}
$$

In the current study, the travel rate of the sensible heat-exchange region is 1.19 times the entering hot salt velocity $\left(u_{i n}\right)$ during a charge process. A similar energy balance can be formulated for a latent heat-exchange region; however, the influence of phase change is dissimilar between the charging and discharging processes in the tank, necessitating separate formulations. In the charging mode, hot molten salt enters at the top of the porous bed and melts the surrounding PCM. The travel rate of this melt front is expressed as follows:

$$
\mathrm{v}_{\text {lat }, \text { chg }}=\frac{\rho_{l, \text { in }} C_{P, l}}{\varepsilon \rho_{l, i n} C_{P, l}+(1-\varepsilon) \rho_{s} C_{P, s}\left[1+\frac{1}{\operatorname{Ste}}\left(\frac{T_{h}-T_{c}}{T_{h}-T_{s o l}}\right)\right]} u_{\text {in }}
$$

Inspection of Eq. 13 reveals that the travel rate of the melt front slows with either increased heat of fusion (nondimensionalized as the inverse Stefan number) or as the solidus temperature approaches the hot operating limit. For the lowest melting point and heat of fusion (case 2), the charging melt front travels at a rate of 0.99 times the velocity of the hot molten salt, while for the highest melting point and heat of fusion (case 11), the travel rate is only 0.15 times the salt velocity. It should be noted that heat exchange in the region of the tank below the solidus 
temperature remains subject to the faster sensible heat transfer rate governed by Eq. 12. This disparity in travel rates deconstructs the porous-bed heat transfer into two separate regions.

Figure 6 illustrates this deconstruction with a plot of molten-salt temperature profile inside the case 5 porous bed during a charge process. Below the solidus temperature, the salt exhibits a sigmoid-shaped temperature profile typical of quartzite-filled thermocline tanks $[25,26]$. Above this point, the salt exhibits a delayed step increase in temperature, corresponding to the slower travel rate of the melt front. The remaining sensible heat exchange at temperatures above the phase change $\left(T>T_{\text {liq }}\right)$ is not governed by Eq. 12 but is instead constrained by the underlying melt front, producing the observed step increase. The axial separation of the two heat-exchange zones is also illustrated in Fig. 6 with a plot of the non-thermal equilibrium or temperature difference between the molten salt and PCM filler. The separation results in an intermediate span of molten salt and PCM in thermal equilibrium at the solidus temperature. As charging progresses, this axial span continues to grow until the leading sensible heat front reaches the tank floor and triggers a saturation condition.

Analogous behavior occurs during the tank discharge process. Cold molten salt enters at the bottom of the porous bed and recovers the latent heat inside the surrounding PCM, solidifying the material. The travel rate of this solidification front is expressed as follows:

$$
\mathrm{v}_{\text {lat }, \text { is }}=\frac{\rho_{l, i n} C_{P, l}}{\varepsilon \rho_{l, i n} C_{P, l}+(1-\varepsilon) \rho_{s} C_{P, s}\left[1+\frac{1}{\operatorname{Ste}}\left(\frac{T_{h}-T_{c}}{T_{l i q}-T_{c}}\right)\right]} u_{i n}^{u}
$$

Eq. 14 shows that the latent heat exchange again slows with increased heat of fusion but also as the liquidus temperature approaches the cold operating limit. This indicates that while tanks with low PCM melting temperatures can utilize the entire latent heat capacity during a charge 
process, the subsequent recovery during a discharge process decreases in response to the slower return rate of the solidification front up the height of the tank.

These trends again illustrate that latent heat thermocline tanks suffer a tradeoff between thermodynamic quality of the PCM filler and corresponding utilization. High melting temperatures $\left(\Theta_{\mathrm{m}}=0.75,0.95\right)$ can support steam generation but exhibit the largest disparity in travel rate between latent and underlying sensible heat exchange during a charge process, resulting in poor utilization. Low melting temperatures $\left(\Theta_{\mathrm{m}}=0.05,0.25\right)$ enable $100 \%$ utilization of the latent heat capacity but cannot support steam generation. However, the corresponding distortion in temperature profile inside the tank enables more sensible heat storage than the baseline quartzite, as seen in Figure 7. This small gain explains the minor increase in annual plant output with low-melting PCM relative to the quartzite-filled tank. The remaining melting temperature considered $\left(\Theta_{\mathrm{m}}=0.5\right)$ falls in the dead zone of the thermocline tank temperature gradient: too cold to support steam generation in the power block and too hot for return of surrounding molten salt to the solar receiver. As a result, the isothermal region between the advancing sensible-heat exchange and the lagging latent heat exchange acts as a choke on the storage capability of the thermocline tank. The corresponding tank stores less heat than the quartzite-filled tank of equal size and enables less power output at a system level.

\subsection{Cascaded latent heat thermocline tank}

The preceding analysis revealed that a latent heat thermocline tank filled with a single phase-change material is unable to substantially outperform a quartzite rock bed with respect to storage capacity or system-level output; however, this barrier may be circumvented with a modified graded filler structure composed of multiple PCMs, each exhibiting a differing melting 
temperature. In this concept, the capsules are organized inside the tank such that the melting temperature increases with axial height; such a tank will be referred to as a cascaded latent heat thermocline tank. Materials with low melting points are located near the bottom while materials with high melting temperatures are located near the top. The different PCMs would be expected to complement each other and result in a latent heat thermocline tank that stores more highquality heat than a quartzite-filled tank of equal size.

The system-level modeling analysis is now extended to investigate the storage performance of a cascaded latent heat thermocline tank. The finite-volume model of the tank porous bed is first segmented into three equal-volume layers along the vertical direction, each composed of a PCM with different melting temperature. Applying the same five user-defined melting points from the previous analysis, a total of eight different cascaded PCM combinations are simulated, as summarized in Table 2. The heat of fusion is fixed at $124.5 \mathrm{~kJ} / \mathrm{kg}(1 / \mathrm{Ste}=0.5)$ for all layers in all cases. As before, each tank model is integrated into the system model and simulated in response to a full year of CSP plant operation. The annual plant performance data (capacity factor and thermal energy discard) are plotted in Figure 8 along with the baseline data for a quartzite-filled tank.

A majority of the cascade structure demonstrate marginal gains over quartzite, as was observed with the previous uniform structures with low melting points. The case D structure exhibits the lowest plant output, with a $20.7 \%$ discard of thermal energy and an annual capacity factor of 0.469 , less than the output achieved with a quartzite-filled tank of equal size. The largest gains are observed with case E, which exhibits only $1.1 \%$ discard of thermal energy and an annual capacity factor of 0.584 . This annual output equates to an additional $45.2 \mathrm{GWh}_{\mathrm{e}}$ or 9.7\% increase over implementation of a quartzite-filled tank of equal size. Given that the 
original motivation for PCM filler is to reduce thermocline tank size, the case E structure can also support a $16 \%$ reduction in tank diameter to match the plant output achieved with quartzite rock filler.

The variation in plant performance for different cascade combinations is explained by the temperature disparity in melting points between the three PCM layers. Among the combinations considered, case D exhibits the largest disparity from top to bottom $(270 \mathrm{~K})$ and achieves the lowest plant output. In contrast, case E exhibits the smallest disparity $(150 \mathrm{~K})$ and achieves the greatest plant output. The three melting points in case $\mathrm{E}$ are also near the mean of the moltensalt temperature span, enabling similar latent heat exchange rates between charging (Eq. 13) and discharging (Eq. 14). While this similarity is desired, the melting points of the top and bottom layers must still remain outside the molten-salt thermal dead zone to avoid the choking phenomenon observed in the previous section with a uniform bed of $\Theta_{\mathrm{m}}=0.5$. Therefore, an optimal three-layer cascaded latent heat thermocline tank should include a top PCM layer that melts slightly above the molten-salt hot supply threshold and a bottom PCM layer that melts slightly below the cold return threshold.

Since particular designs of the cascade latent heat thermocline show improvement in energy storage over a conventional quartzite rock bed, it is reiterated that the current study applies a hypothetical PCM with a high thermal conductivity of $5 \mathrm{~W} / \mathrm{m}-\mathrm{K}$. Suitable candidates for phase change materials (such as nitrate and carbonate salts) exhibit much lower conductivities on the order of $0.5 \mathrm{~W} / \mathrm{m}-\mathrm{K}$, which would induce large temperature gradients inside the capsule and inhibit energy transfer with the surrounding heat transfer fluid. Additional consideration must also be directed towards the cost and physical stability of the encapsulated PCM. Long-term compatibility of the capsules with hot and cold molten salt should be verified 
with immersion tests similar to previous investigations of quartzite rock [1]. The economic benefit of the latent heat mechanism, either from increased plant revenue or from cost savings with tank size reduction, must also justify any material and fabrication expenses related to encapsulation.

\section{Conclusions}

A new computational model using a finite-volume method is developed to simulate mass and energy transport inside a thermocline tank filled with encapsulated phase-change material. A hypothetical PCM is applied to enable a one-to-one comparison with conventional quartzite rock filler. The storage model is then integrated into a system-level model of a $100 \mathrm{MW}_{\mathrm{e}}$ molten-salt power tower plant to inform storage behavior with realistic solar collection and steam generation processes. A parametric study of hypothetical PCM melt properties is conducted with this system model to ascertain the viability of latent heat as a replacement for quartzite rock.

Thermocline tanks filled with only a single PCM exhibit a persistent tradeoff between the thermodynamic quality of the PCM and the corresponding utilization of the added latent heat inside the tank. Low melting temperatures are well-utilized with complete phase change, but provide marginal energy benefits for steam generation in the power block. In contrast, high melting temperatures can support steam generation but are not utilized to a sufficient extent. This trend is an inherent limitation of energy transfer inside a dual-media thermocline tank.

Modification of the porous bed with a cascaded PCM structure increases the utilization of the latent heat and can provide significant improvement over conventional quartzite rock filler. For a user-defined PCM heat of fusion of $124.5 \mathrm{~kJ} / \mathrm{kg}(1 /$ Ste $=0.5)$, a three-layer cascade 
structure yields either a $9.7 \%$ increase in annual power output or a $16 \%$ decrease in thermocline tank diameter relative to a quartzite-filled tank; however, this benefit remains highly sensitive to the selected melting points relative to the temperature thresholds for tank supply (steam generation) and tank return (solar heating). Further work is needed to identify suitable phasechange materials, demonstrate encapsulation and molten-salt compatibility, and quantify economic benefits.

\section{Acknowledgements}

This paper is based upon work supported in part under the US-India Partnership to Advance Clean Energy-Research (PACE-R) for the Solar Energy Research Institute for India and the United States (SERIIUS), funded jointly by the U.S. Department of Energy (Office of Science, Office of Basic Energy Sciences, and Energy Efficiency and Renewable Energy, Solar Energy Technology Program, under Subcontract DE-AC36-08GO28308 to the National Renewable Energy Laboratory, Golden, Colorado) and the Government of India, through the Department of Science and Technology under Subcontract IUSSTF/JCERDC-SERIIUS/2012 dated $22^{\text {nd }}$ Nov. 2012. 


\section{Nomenclature}

$\mathrm{C}_{\mathrm{p}} \quad$ specific heat, $\mathrm{J} / \mathrm{kg}-\mathrm{K}$

e mushy region half span, $\mathrm{K}$

E energy, J

F inertial coefficient, -

$\mathrm{F}_{\mathrm{s}} \quad$ solid fraction, -

g gravitational constant, $\mathrm{m} / \mathrm{s}^{2}$

$\mathrm{h} \quad$ porous bed height, $\mathrm{m}$

$\mathrm{h}_{\mathrm{fs}} \quad$ heat of fusion, $\mathrm{J} / \mathrm{kg}$

$\mathrm{h}_{\mathrm{i}} \quad$ interstitial convection coefficient, $\mathrm{W} / \mathrm{m}^{2}-\mathrm{K}$

i current porous bed cell, -

$\mathrm{k}_{\text {eff }}$ effective thermal conductivity, W/m-K

$\mathrm{K} \quad$ permeability, $\mathrm{m}^{2}$

L latent heat, $\mathrm{J} / \mathrm{kg}$

m mass, $\mathrm{kg}$

$\mathrm{N}$ number of porous bed cells, -

$\mathrm{p}$ pressure, $\mathrm{Pa}$

Ste Stefan number, -

$\mathrm{t}$ time, $\mathrm{s}$

T temperature, ${ }^{\circ} \mathrm{C}$

u molten-salt velocity, $\mathrm{m} / \mathrm{s}$

U utilization, -

$\mathrm{V}$ heat-exchange region travel rate, $\mathrm{m} / \mathrm{s}$ 
$\mathrm{x}$ axial location, $\mathrm{m}$

\section{Greek}
$\varepsilon \quad$ porosity, -
$\Theta \quad$ nondimensional temperature, -
$\mu \quad$ viscosity, $\mathrm{Pa}-\mathrm{s}$
$\rho \quad$ density, $\mathrm{kg} / \mathrm{m}^{3}$
$\tau \quad$ stress tensor, $\mathrm{N} / \mathrm{m}^{2}$

\section{Subscript}

$\begin{array}{ll}\text { ch } & \text { cold limit } \\ \text { chg } & \text { charge mode } \\ \text { dis } & \text { discharge mode } \\ \text { h } & \text { hot limit } \\ \text { heel } & \text { liquid heel } \\ \text { in } & \text { inlet } \\ \text { l } & \text { molten-salt region } \\ \text { lat } & \text { latent heat } \\ \text { liq } & \text { liquidus point } \\ \text { m } & \text { melting point } \\ \text { s } & \text { filler region } \\ \text { sen } & \text { sensible heat } \\ \text { sol } & \text { solidus point }\end{array}$




\section{References}

[1] J. E. Pacheco, S. K. Showalter, W. J. Kolb. Development of a molten-salt thermocline thermal storage system for parabolic trough plants. ASME J Sol Energy Eng 2002;124:153-9.

[2] S. E. Faas, L. R. Thorne, E. A. Fuchs, N. D. Gilbertsen. 10 MWe solar thermal central receiver plant: thermal storage subsystem evaluation - final report, SAND86-8212. Sandia National Laboratories; 1986.

[3] Z. Yang, S. V. Garimella. Molten-salt thermal energy storage in thermoclines under different environmental boundary conditions. Appl Energ 2010;87:3322-9.

[4] J. T. Van Lew, P. Li, C. L. Chan, W. Karaki, J. Stephens. Analysis of heat storage and delivery of a thermocline tank having solid filler material. ASME J Sol Energy Eng 2011;133:021003.

[5] G. J. Kolb. Evaluation of annual performance of 2-tank and thermocline thermal storage systems for trough plants. ASME J Sol Energy Eng 2011;133:031023.

[6] C. Xu, Z. Wang, Y. He, X. Li, F. Bai. Sensitivity analysis of the numerical study on the thermal performance of a packed-bed molten salt thermocline thermal storage system. Appl Energ 2012;92:65-75.

[7] S. M. Flueckiger, B. D. Iverson, S. V. Garimella, J. E. Pacheco. System-level simulation of a solar power tower plant with thermocline thermal energy storage. Appl Energ 2014;113:86-96.

[8] S. Flueckiger, Z. Yang, S. V. Garimella. An integrated thermal and mechanical investigation of molten-salt thermocline energy storage. Appl Energ 2011;88:2098-105.

[9] S. M. Flueckiger, Z. Yang, S. V. Garimella. Thermomechanical simulation of the Solar One thermocline storage tank. ASME J Sol Energy Eng 2012;134:041014.

[10] S. Pendyala, P. Sridharan, S. Kuravi, C. K. Jotshi, M. K. Ram, M. Rahman, et al. Macroencapsulation of sodium nitrate for thermal energy storage in solar thermal power. Proceedings of the ASME 2012 6th International Conference on Energy Sustainability, San Diego, CA: 2012.

[11] A. Felix Regin, S. C. Solanki, J. S. Saini. An analysis of a packed bed latent heat thermal energy storage system using PCM capsules: Numerical investigation. Renew Energ 2009;34:1765-73.

[12] K. Nithyanandam, R. Pitchumani, A. Mathur. Analysis of a latent thermocline energy storage system for concentrating solar power plants. Proceedings of the ASME 2012 6th International Conference on Energy Sustainability, San Diego, CA: 2012.

[13] D. A. Nissen. Thermophysical properties of the equimolar mixture NaNO3-KNO3 from 300C to 600C. J Chem Eng Data 1982;27:269-73.

[14] J. E. Pacheco, M. E. Ralph, J. M. Chavez, S. R. Dunkin, E. E. Rush, C. H. Ghanbari, et al. Results of molten salt panel and component experiments for solar central receivers, SAND94-2525. Sandia National Laboratories; 1995.

[15] Z. Yang, S. V. Garimella. Thermal analysis of solar thermal energy storage in a molten-salt thermocline. Sol Energy 2010;84:974-85.

[16] J. Cote, J.-M. Konrad. Thermal conductivity of base-coarse materials. Can Geotech J 2005;42:61-78.

[17] E. E. Gonzo. Estimating correlations for the effective thermal conductivity of granular materials. Chem Eng J 2002;90:299-302. 
[18] N. Wakao, S. Kaguei. Heat and Mass Transfer in Packed Beds. New York: Gordon Beach; 1982.

[19] V. R. Voller, C. Prakash. A fixed grid numerical modelling methodology for convectiondiffusion mushy region phase-change problems. Int J Heat Mass Transfer 1987;30:170919.

[20] B. L. Kistler. A user's manual for DELSOL3, SAND86-8018. Sandia National Laboratories; 1986.

[21] M. C. Stoddard, S. E. Faas, C. J. Chiang, J. A. Dirks. SOLERGY, SAND86-8060. Sandia National Laboratories; 1987.

[22] J. E. Pacheco. Final test and evaluation results from the Solar Two project, SAND20020120. Sandia National Laboratories; 2002.

[23] G. J. Kolb. An evaluation of possible next-generation high-temperature molten-salt power towers, SAND2011-9320. Sandia National Laboratories; 2011.

[24] Electric Power Research Institute. Solar thermal storage systems: preliminary design study, 1019581. EPRI; 2010.

[25] S. M. Flueckiger, S. V. Garimella. Second-law analysis of molten-salt thermal energy storage in thermoclines. Sol Energy 2012;86:1621-31.

[26] Z. Yang, S. V. Garimella. Cyclic operation of molten-salt thermal energy storage in thermoclines for solar power plants. Appl Energ 2013;103:256-65. 
Table 1: Case summary of inverse Stefan number and melting temperature for PCM filler in a latent heat thermocline tank.

\begin{tabular}{ccc}
\hline Case & 1/Ste & $\boldsymbol{\Theta}_{\mathbf{m}}$ \\
\hline 1 & 0 & N/A \\
2 & 0.25 & 0.05 \\
3 & 0.25 & 0.25 \\
4 & 0.25 & 0.5 \\
5 & 0.25 & 0.75 \\
6 & 0.25 & 0.95 \\
7 & 0.5 & 0.05 \\
8 & 0.5 & 0.25 \\
9 & 0.5 & 0.5 \\
10 & 0.5 & 0.75 \\
11 & 0.5 & 0.95 \\
\hline
\end{tabular}


Table 2: Case summary of melting temperatures $\left(\Theta_{\mathrm{m}}\right)$ in a three-layer cascade structure for a latent heat thermocline tank. All PCMs are assumed to have a latent heat capacity that corresponds to an inverse Stefan number of 0.5.

\begin{tabular}{cccc}
\hline Case & Top layer & Middle layer & Bottom layer \\
\hline A & 0.75 & 0.25 & 0.05 \\
B & 0.95 & 0.25 & 0.05 \\
C & 0.75 & 0.5 & 0.05 \\
D & 0.95 & 0.5 & 0.05 \\
E & 0.75 & 0.5 & 0.25 \\
F & 0.95 & 0.5 & 0.25 \\
G & 0.95 & 0.75 & 0.05 \\
H & 0.95 & 0.75 & 0.25 \\
\hline
\end{tabular}




\section{List of Figures}

1. Thermal stratification of hot and cold molten salt inside a conventional rock-filled thermocline tank. Hot molten salt for steam generation (supply zone) is stored at the top while cold salt for solar heating (return zone) is stored at the bottom. Temperature limits for both solar plant processes result in an intermediate thermal dead zone that cannot exit the thermocline tank.

2. Schematic illustration of a molten-salt latent heat thermocline tank, including the porous bed generated with encapsulated PCM and the pure liquid heel. Hot salt is supplied at the liquid heel through the top manifold and is extracted via the hot pump. Cold salt enters the porous bed through the bottom manifold but is also extracted through the manifold via the cold pump.

3. Steam generators and steam Rankine cycle layout. Supplied molten salt enters at the superheater and exits from the preheater. In the Rankine cycle, LP is the low pressure pump and HP is the high pressure pump.

4. Annual power tower plant performance with respect to PCM melting temperature: (a) capacity factor and (b) thermal energy discard. The dashed lines illustrate a conventional quartzite-filled tank with no latent heat capacity.

5. Maximum utilization of thermal energy capacity (corresponding to tank saturation for a single day during year-long simulation) with respect to the PCM melting temperature: (a) sensible heat and (b) latent heat.

6. Molten-salt temperature profile for case $5\left(1 / \mathrm{Ste}=0.25, \Theta_{\mathrm{m}}=0.75\right)$ during a charge process. Below the solidus temperature, heat exchange between the molten salt and filler is sensible. Above the solidus temperature, the influence of latent heat distorts the temperature profile and results in a second heat-exchange region. These two regions are distinguished by the magnitude of thermal non-equilibrium between the molten salt and filler, plotted on the second y-axis.

7. Normalized molten-salt temperature profiles inside the thermocline tank at saturation for case 1 (quartzite rock) and case $3\left(1 / \mathrm{Ste}=0.25, \Theta_{\mathrm{m}}=0.25\right)$. The step increase in the temperature profile above the melting region enables the PCM-filled tank to store more sensible heat at saturation than quartzite indicated by the higher temperatures observed near the floor of the thermocline tank. The improvement is limited to scenarios where the PCM melting temperature is below the molten-salt return threshold. 
8. Annual power tower plant performance with a cascaded latent heat thermocline tank: (a) capacity factor and (b) thermal energy discard. The dashed lines illustrate a conventional quartzite-filled tank with no latent heat capacity. Substantial benefits only occur when the top and bottom melting points are close to the respective threshold molten-salt supply and return temperatures, represented by case $\mathrm{E}$. 